\title{
ПЕРСПЕКТИВЫ ВЫХОДА УКРАИНСКИХ КОМПАНИЙ НА МИРОВОЙ РЫНОК ІРО
}

В статье сформулированы современные тенденции мирового рынка первичных публичных размещений акций. Обоснованы практические рекомендации для успешного выхода украинских компаний на международные рынки IPO.

\section{1. ВВЕДЕНИЕ}

Активизация процессов выхода на международный рынок IPO украинских компаний позволит им привлечь масштабные и долгосрочные средства для технологической модернизации, расширения производства и сбыта, укрепления конкурентоспособности на отечественном и зарубежных рынках.

Украинские компании за последние пять лет провели 59 размещений и привлекли $\$ 6,2$ млрд. Это составило 0,9\% мировых объемов по количеству размещений и $0,6 \%$ объемов привлеченных средств (см. табл.1).

Таблиця 1. Показатели мирового и украинского рынка IPO за период 2006-2010гг

\begin{tabular}{|l|c|c|c|}
\hline \multicolumn{1}{|c|}{ Показатель } & Мир & Украина & Украина/Мир \\
\hline Рост капитализации, \$млрд. & 1056 & 6,2 & $0,6 \%$ \\
\hline Количество соглашений & 6549 & 59 & $0,9 \%$ \\
\hline $\begin{array}{l}\text { Средний размер соглашения, } \\
\text { \$млрд. }\end{array}$ & 161 & 105 & $65,2 \%$ \\
\hline
\end{tabular}

Таким образом, IPO как инструмент привлечения капитала недостаточно используется украинскими компаниями, хотя есть хорошие перспективы для его развития. Ограничительными факторами для процессов выхода украинских компаний на IPO являются: длительная подготовка, нежелание отечественного бизнеса публиковать свою отчетность, низкий уровень корпоративного управления, невысокая ликвидность украинского фондового рынка, нерациональная система налогообложения, недостаточный уровень инвестиционной привлекательности компаний и низкий рейтинг инвестиционного климата страны, отсутствие государственных гарантий прозрачности инвестиционных процессов и защиты прав инвесторов.

Теоретические и практические аспекты проблемы развития международных финансовых рынков и привлечения средств через IPO исследовали такие украинские ученые как Базилевич В.Д., Бланк И.А., Гаврилюк О.В., Губский Б.В., Крылова Н.В., Козаков В., Козюк В.В., Мельник В.В., Пересада А., Рокоча В.В.,

${ }^{1}$ Dr Tatiana Nagachevskaia, Katedra Międzynarodowej Ekonomji Kijowskiego Narodowego Uniwersytet im. Tarasa Szewczenka, Ukraina. 
Рогач О.И., Старостина А.О., Софищенко И.Я., Шевченко В.Ю. и др., а также зарубежные ученые: Росс Геддес, Дж. Риттер, Л.Дж. Гитман, М.Д. Джонк, Д. Червитц, Ф. Корнелли, П. Спиндт, М. Бреннан, Дж. Франкс, Ц. Казерер, Д. Ширек, С. Перистиани, А. Лукашов, Е.Лебедева, А. Могин, А. Напольнов, С. Гвардина и др. В научной литературе недостаточно исследованы особенности механизмов IPO компаний стран с переходной экономикой и отраслевые аспекты рынка IPO.

Решение управленческой проблемы активизации выхода на международные рынки IPO требует постоянного мониторинга этого рынка, отслеживания основных показателей и тенденций, механизмов и инструментов, оценки перспектив с целью разработки успешного стратегического плана первичного публичного размещения акций.

\section{2. АНАЛИЗ ТЕНДЕНЦИЙ РАЗВИТИЯ МИРОВОГО РЫНКА ІРО}

За период с 1996 по 2011 год мировой рынок IPO динамично развивался, с каждым годом растет его капитализация (см. рис.1.). Но вместе с тем, он достаточно зависим от внешних факторов. За этот период было три спада активности: в 1998 г., с 2001 по 2003 гг. и в кризисный период - 2008-2009 гг. Докризисный 2007 год был пиковым в истории рынка IPO по количеству соглашений - 2014 и по объему годовой капитализации - \$295 млрд. В 2008 г. произошло резкое падение основных показателей рынка IPO: количества соглашений - в 2,6 раза и капитализации - в 3,1 раза.

Рис. 1. Динамика мирового рынка IPO, млрд. дол. США [1, 2].

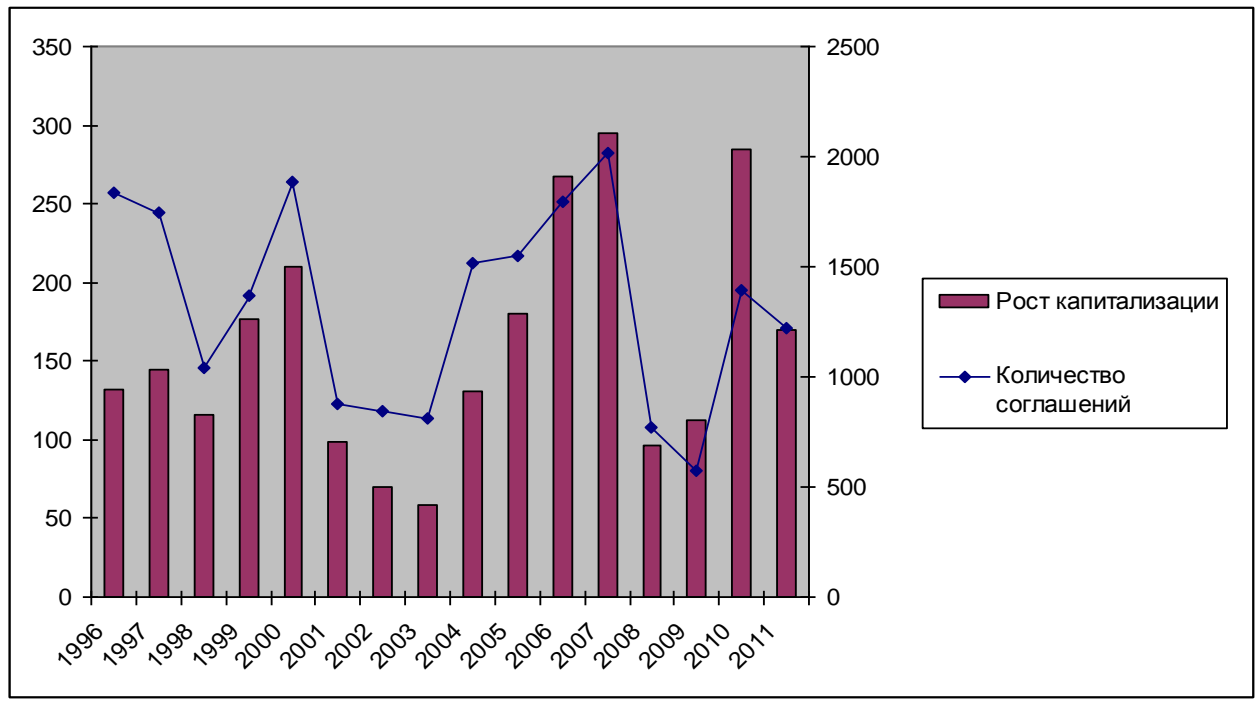

Глобальная активность IPO достигла докризисного уровня в 2010 г., показатель капитализации составил \$285 млрд. при количестве соглашений 1393. После двухгодовой пассивной активности на рынке IPO во время глобального 
финансового кризиса и рецессии происходит оздоровление. Мировой рынок IPO начал стремительно расти в первых трех кварталах 2010 г., хотя инвесторы были обеспокоены долгом Еврозоны, значительными регулятивными изменениями, сокращением государственных пакетов по стимулированию и осторожным доступом к кредитам.

Несмотря на глобальные макроэкономические риски и долговой кризис, на глобальных рынках IPO проявляется тенденция к возростанию. При этом, основными факторами роста глобального рынка IPO были следующие:

- д дефицит капитала в условиях затянувшегося периода выхода из кризиса;

- значительное количество отложенных с начала кризиса листингов;

- рост на развивающихся рынках;

- процессы государственной приватизации;

- „spin-off” многонациональных компаний и компаний энергетической отрасли, промышленности, технологическом секторе и секторе материалов;

- $\quad$ возрастающее доверие инвесторов к оценке акций и рисков.

Процессы IPO были ограничены следующими факторами: финансовоэкономическая нестабильность в еврозоне, политическая нестабильность (в т.ч. события “арабской весны”), значительная турбулентность в Азии, снижение агентством Standard \& Poor's кредитного рейтинга США, высокое значение индексов рыночной волатильности в США, Великобритании и Гонконге, отсутствие доверия инвесторов. Нестабильное положение на международных фондовых рынках привело к снижению индексов, что, в свою очередь, отрицательно сказалось на показателе отношения рыночной стоимости акции к прибыли на акцию по сделкам IPO.

В 2011 г. активность мирового рынка IPO несколько уменшилась и характеризовалась следующими показателями:

- $\quad$ количество соглашений составило 1 225, что на $12 \%$ ниже, чем в 2010 г., но в 1,6 раза выше, чем в 2008г.;

- капитализация уменшилась на $40 \%$ - с $\$ 284,6$ млрд. до $\$ 169,9$ млрд., но оказалась в 1,8 раза выше, чем в 2008г.;

- $\quad$ средний размер соглашения составил \$139 млн. против \$204 млн. в 2010 году (см. рис.2);

- $\quad$ ТОП 5 секторов по количеству соглашений: материалы (268), промышленность (199), высокие технологии (149), товары первой необходимости (124) и энергетика (110). Причем, общее количество соглашений на мировом рынке IPO в 2011 году уменшилось, но в секторах товаров первой необходимости и энергетики выросло;

- $\quad$ ТОП 5 секторов по капитализации: материалы (\$29,2 млрд.), промышленность (\$26,4 млрд.), энергетика (\$21,3 млрд.), финансы (\$15,9 млрд.) и высокие технологии (\$14,7 млрд.). Сектор финансов утратил первенство и занял 4-ое место;

- $\quad$ ТОП 5 фондовых бирж по количеству соглашений: Шеньчженская - ChiNext (128), Варшавская - New Connect (123); Шеньчженская - SME (115), Австралийская (101), Гонконгская (68). Нью-Йоркская фондовая биржа не ввошла в пятерку, а на Варшавской NewConnect было осуществлено 10\% соглашений мирового рынка IPO; 
- ТОП 5 фондовых бирж по капитализации: Нью-Йоркская (\$30,5 млрд.), Гонконгская (\$25,3 млрд.), Шеньчженская-SME (\$15,7 млрд.), Шанхайская (\$15,1 млрд.) и Лондонская (\$13,9 млрд.). Токийская биржа не ввошла в ТОП 5 $[1,2]$.

Рис. 2. Средний размер соглашения IPO, млн. дол. США $[1,2]$.

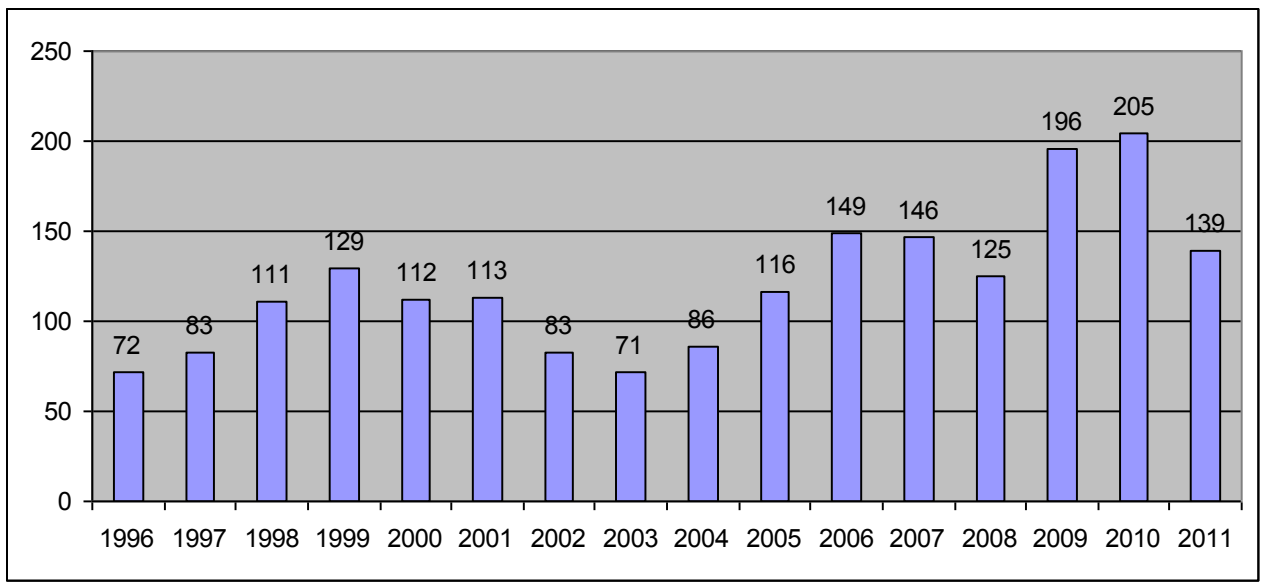

В отраслевой структуре компаний, которые вышли с IPO наибольшая часть относится к финансовому сектору и обеспечивающих развитие инфраструктуры. Финансовый сектор привлек в 2010г. \$80 млрд., т.е. 28\% от мировой капитализации. Этот показатель обеспечили три наибольшие азийские страховые компании: AIA, Dai-ichi Life Insurance, Samsung Life Insurance Co. Ltd. Лидировали следующие секторы: материалы, промышленность, высокие технологии, товары первой необходимости, энергетика.

Средняя доходность инвесторов в сделках IPO в 2011 году составила 13,3\%, что в 2 раза ниже, чем в 2010 году, когда доходность от вложений достигла 26,4\%.

Рынок IPO развивающихся стран составляет 69\% от мирового: \$195,3 млрд. и 983 компании, которые вышли с IPO. Значительную часть $(41 \%, \$ 81,1$ млрд.) привлекли предприятия государственной собственности. Также, значительную часть компаний-эмитентов составили компании Китая - 67 с несколькими большими IPO.

IPO-активность в регионе Центральной и Восточной Европы превышает общемировую. За 9 месяцев 2011 года она возросла, в то время как мировые объемы IPO снизились на 6,7\% по сравнению с аналогичным периодом 2010 г.

Появилась новая особенность процессов IPO. Некоторые эмитенты IPO используют его в качестве инструмента спасения от банкротства. И достаточно успешно. Перед выходом на IPО они умело скрывают свое финансовое состояние и делают акценты на перспективе. Можно предположить, что в долгосрочной перспективе результативность таких IPO будет ниже, поскольку привлеченные средства направляются не в основные фонды, повышая стоимость активов компании, а на погашение кредитов и долгов. 
Eвpona. В 2011 году в Европе было осуществлено несколько крупных размещений, причем наиболее заметные IPO были проведены на биржах в Лондоне, Мадриде и Варшаве. В 2011 году в Европе в общей сложности было проведено 430 сделок IPO на общую сумму 26,5 млрд евро, что на $13 \%$ больше в сравнении с 2010 годом по количеству сделок и на 1\% - по объему привлеченных средств [2]. Произошло снижение среднего объема размещения на 10\% - с 86 млн. евро в 2010 году до 77 млн. евро в 2011 году под влиянием фактора давления на цены. На европейском рынке IPO более высокая активность наблюдалась в 1-ом полугодии 2011 года, в течении которого было привлечено 62\% годовых объемов.

Если в 2011 году Европа стала единственным регионом где был отмечен рост как по количеству сделок, так и по объему привлеченных средств, то во II квартале 2012 года в результате сложной экономической ситуации произошло снижение уровня IPO активности на 68\% против 1 квартала. Было привлечено только 915 млн. долл. США в результате 46 IPO (лишь $2 \%$ от мирового объема капитала, привлеченного в этом квартале) по сравнению с 2,9 млрд. долл. США, привлеченными в результате 39 сделок в I квартале 2012 года. Очевидно, что и эмитенты, и инвесторы наблюдают, насколько успешно Европа сможет справиться с кризисом суверенного долга. Во II квартале 2012 г. наибольшая активность по количеству сделок была отмечена на Варшавской биржевой площадке NewConnect, лондонском Альтернативном инвестиционном рынке и Стамбульской фондовой бирже. Наблюдается рост количества сделок по привлечению компаниями малого бизнеса средств для финансирования своей деятельности, что приводит к уменьшению среднего объема сделок. В основном сделки заключались компаниями сектора технологий, потребительских товаров, товаров повседневного спроса и промышленными компаниями.

Среди фондовых площадок Европы лидируют Лондон и Варшава. Более половины средств, привлеченных в Европе, а именно 14,1 млрд евро, приходится на Лондонскую фондовую биржу, хотя в Лондоне была проведена лишь $25 \%$ всех IPO в Европе. В Варшаве было заключено наибольшее число сделок, но с более низким средним объемом размещения.

В 2011 году на европейских рынках доминировали крупные сделки, количество которых было незначительным: в результате шести крупнейших сделок было привлечено 16 млрд евро, что составляет 60\% от общей суммы средств, привлеченных в рамках IPО в Европе, по сравнению с 37\% (9,6 млн евро) в 2010 году.

На Лондонской фондовой бирже проходили листинги в основном компаний сырьевого сектора, которые в результате IPO привлекли 8,2 млрд евро; на долю этих компаний пришлось 58\% от общего числа сделок на Лондонской фондовой бирже. Размещение акций компании Glencore, торгующей сырьевыми товарами, принесло ей 6,9 млрд евро и включение в индекс FTSE 100. Эта сделка стала крупнейшей в Лондоне и способствовала увеличению объемов привлеченных средств в рамках IPO в лондонском Сити в течение 2011 года. На три крупнейших листинга в Лондоне - IPO компании Glencore, нефтегазового предприятия Vallares и инвестиционной компании Justice Holdings - пришлось более 9 млрд. евро от общей суммы привлеченных в Лондоне средств. Почти $28 \%$ привлеченных Европой средств было привлечено в результате приватизации объектов государственной собственности в Испании и Польше, осуществленной летом 2011 года [2]. 
Гонконг занимает лидирующие позиции на мировом рынке IPO. Международные компании и компании сектора элитных брендов все чаще обращают свои взоры в сторону рынков Азиатско-Тихоокеанского региона для реализации планов по расширению деятельности и привлечению капитала. Кроме того, благодаря листингу в этом регионе международные компании могут укрепить свой бренд и свой имидж на новых рынках. Уникальное расположение Гонконга превращает его в идеальную платформу для встреч международных компаний с китайскими инвесторами.

Можна выделить следующие ключевые тенденции мирового рынка IPO:

Глобализачия мирового рынка IPО и рост количества международных сделок IPO. Первичное публичное размещение акций проводилось в большинстве стран мира, и многие размещения были международными. Если раньше существовало мнение, что акции крупной компании должны котироваться в Нью-Йорке или Лондоне, чтобы привлечь значительный объем капитала, то теперь ситуация меняется. Так, из 1225 IPO в 2011 году лишь 67 (5,5\%) было проведено на НьюЙоркской фондовой бирже, хотя она продолжает лидировать по объемах привлеченных средств через IPO (18\% от мирового). Вместе с тем, наиболее крупное в истории IPO - государственный коммерческий банк «Сельськохозяйственный банк Китая» привлек \$22,1 млрд. было проведено в Гонконге и Шанхае.

Мировые фондовые площцдки конкурируют между собой за первенство на мировом рынке $u$ за клиентов-эмитентов. Биржи различаются требованиями к эмитентам, техническими параметрами, нормами и стандартами регулирования, системой отчетности. Компаниям следует выбирать тот фондовый рынок, который соответствует целям публичного размещения и способствует росту привлекательности акций для инвесторов. При выборе подходящей фондовой биржи компании должны учитывать различные факторы, в том числе: ликвидность рынка; стоимость капитала; географическое положение; отраслевую структуру рынка; затраты на соблюдение нормативно-законодательных требований; требования к корпоративному управлению; местонахождение ключевых инвесторов; временные рамки для IPO; вопрос престижа и мировое признание. Растет количество слияний и поглощений бирж, ведутся переговоры о новых сделках. Сами биржи наращивают свою капитализацию и выходят на IPO. С одной стороны, происходит усиление регулирования и ужесточение условий листинга, с другой стороны, биржи реагируют на потребность клиентов снизить затраты. Ведущие крупные биржи создают альтернативные площадки с более мягкими условиями для входа.

Рост активности компаний-эмитентов со стран с переходной экономикой и развивающихся стран. IPO перестали быть прерогативой развитых экономик США, стран Западной Европы и Азии. Происходит смещение баланса в сторону растущих рынков. Для многих крупных инвесторов капиталовложения в Россию, Индию и Китай являются неотъемлемой частью глобальной стратегии развития. Растет интерес и к другим развивающимся рынкам; в частности, внимание инвесторов привлекают компании из Польши, Украины, Казахстана, Бразилии, Израиля, Малайзии, Южной Кореи. Наиболее привлекательными площадками для компаний из стран СНГ есть Варшавская и Лондонская биржы. Рынки Великобритании отличаются высокой ликвидностью, и в то же время они менее 
жестко регулируются по сравнению с рынками США, что делает листинг в Лондоне более быстрым и дешевым. На Варшавской фондовой бирже еще меньше требования листинга и затраты, а также польським инвесторам более знаком стиль ведения бизнеса компаний-выходцев с соседних стран.

Выход на международное IPО становится для многих компаний главной стратегической целью. Если раньше IPO рассматривалось как один из возможных альтернативных инструментов привлечения капитала, рядом с еврооблигационными займами, банковскими кредитами, АДР, лизингом, венчурным капиталом, и др., то сейчас IPO является безусловным приоритетом. Вместе с тем, выпуск еврооблигаций или привлечение синдицированных кредитов по низким процентным ставкам позволяют корпорациям осуществить финансирование, не выходя на открытый рынок.

В аналитическом отчете “Global IPO Trends 2012” эксперты компании Ernst\&Youngst формулируют ряд трендов и особенностей глобального рынка IPO, а также дают практические рекомендации компаниям-кандидатам на IPO.

Умение вести бизнес в условиях волатильности. Поскольку в 2011 году важнейшим фактором, влияющим на мировые рынки IPO, была волатильность, рекомендуется отслеживать индекс волатильности Чикагской фондовой биржи (VIX), рассчитываемый для опционов по индексу S\&P 500. Значение индекса VIX, превышающее 20-25\%, означает, что волатильность находится на таком уровне, при котором активность на рынках IPO фактически прекращается. В первой половине 2011 года наблюдалась тенденция к снижению индекса VIX, однако в середине года он повысился на фоне развития долгового кризиса в Европе и снижения кредитного рейтинга США. Компаниям следует ожидать спада волатильности, но в ближайшей перспективе на принятие решений по сделкам IPO будет влиять непредсказуемость рынка.

Управление риском при реализачии сделок IРО. Повышение уровня риска, связанного с реализацией сделок, требует взвешенной оценки стоимости ценных бумаг и изменения подхода, используемого компаниями при планировании IPO. С одной стороны, инвесторы стали достаточно терпимо относиться к компаниям, которые заявляют о своих планах по проведению IPO, а затем откладывают листинг до наступления благоприятного момента. Однако в отношении компаний, принявших решение о проведении сделки на рынке, а затем отказавшихся от своих планов из-за отсутствия поддержки, отношение инвесторов будет более острожным и менее благожелательным.

Заблаговременная подготовка - залог успеха. Более ранняя подготовка к листингу и готовность оперативно реагировать на появление подходящей возможности на рынке являются сейчас факторамы успешного IPO. Кандидаты на IPO должны подготовить полную характеристику деятельности компании, прозрачную финансовую отчетность и заинтересовать инвесторов описанием перспектив. Также, необходимо оценить риски, которые могут замедлить или остановить процесс размещения акций на бирже.

Компаниям следует избегать стандартных решений при выборе площзадки для размещения акций $и$ всесторонне проанализировать все существуюшие возможности привлечения финансирования. Ряд европейских компаний выбрали для проведения IPO не национальные фондовые рынки, а рынки стран Азии или США. В 2011 году европейскими компаниями было осуществлено 96 
международных сделок IPO [2]. Для компаний, планирующих IPO, стали более привлекательными современные формы долевого финансирования, такие как порталы краудфандинга (crowdfunding), позволяющие получить прямой доступ к инвесторам, а также новые участники рынка в виде крупных многосторонних торговых площадок.

Перспективы восстановления рынка IPO зависят от решений центральных банков $u$ правительств. Европа добилась определенного успеха в решении финансово-долговых проблем, в США также наблюдается улучшение экономической ситуации, но устойчивое восстановление рынка IPО будет зависеть от последующих эффективных решений центральных банков и правительств.

Инвесторов интересуют компании, которые приносят прибыль. Для того, чтобы рынок IPO начал динамично развиваться, необходимы две составляющие: прибыльные компании, нуждающиеся в инвестициях, и оптимистичные настроения на фондовом рынке. Ожидается продолжение тенденции роста прибыли компаний из списка S\&P 500, азиатских компаний, промышленных и технологических компаний.

Размещение незначительной части акций по опыmy Facebook. Компании из других отраслей, планирующие IPO, могут извлечь полезную информацию из опыта социальных сетей и интернет-компаний, недавно разместивших свои акции на фондовых биржах. Для поддержания курса предложения на высоком уровне и минимизации риска, связанного с реализацией сделки, компании могут размещать относительно небольшие доли от общего капитала.

Фонды прямых инвестиций и фирмы с участием венчурного капитала будут активными участниками рынка IPO. Фонды прямых инвестиций и фирмы с участием венчурного капитала провели успешные IPO и привлекли значительные средства. Свободные средства в распоряжении фондов прямых инвестиций в мае 2012 года составляли 375 млрд. дол. США, а фирм с участием венчурного капитала - 115 млрд. дол. США [1].

\section{3. ОСОБЕННОСТИ ВЫХОДА УКРАИНСКИХ КОМПАНИЙ НА МЕЖДУНАРОДНЫЕ IPO}

Характерными особенностями и тенденциями выхода украинских компаний на международные фондовые рынки являются следующие:

- на международные IPO выходят украинские эмитенты преимущественно аграрного сектора, металургии, пищевой промышленности, строительства и недвижимости;

- средний размер IPО ниже среднемирового уровня;

- $\quad$ на IPО выходят преимущественно крупные компании, которые имеют средства для подготовки;

- позиционирование эмитентов - компании страны относящейся к группе растущих рынков, темпы роста экономики выше среднемировых, большая емкость внутреннего рынка Украины;

- выше рентабельность бизнеса;

- $\quad$ недооцененные рынком активы, которые имеют значительный потенциал роста капитализации; 
- компании-эмитенты привлеченные средства вкладывают в технологическую модернизацию и расширение бизнеса;

- основными площадками для украинских компаний выступают Лондонская альтернативная, Варшавская, Нью-Йоркская фондовые биржи. Для небольших компаний Варшава остается основной площадкой.

Варшавская фондовая биржа в 2011 году занимает третью позицию на рынках, регулируемых ЕС, по общему объему размещения: на бирже была проведена 31 сделка IPO, в рамках которых привлечено 2067 млн евро. Стоит отметить, что в 2011 г. по сравнению с 2010 г. сумма привлеченных на бирже средств снизилась на $45 \%$, а количество сделок увеличилось на 19\%. Большой вклад в улучшение показателей Варшавской фондовой биржи внесла сделка по приватизации предприятия Jastrzębska Spółka Weglowa, контролируемой государством польской компании по производству коксующегося угля. Сумма поступлений по сделке составила 1346 млн. евро, а сама сделка стала четвертым по величине первичным публичным размещением в 2011 году.

На биржевой площадке Варшавской фондовой биржи NewConnect число сделок IPO удвоилось - с 86 в 2010 году до 172 в 2011 году, что позволило ей занять по этому показателю 1-ое место в Европе среди рынков, регулируемых биржами. За этот же период сумма привлеченных средств возросла более чем в три раза - с 40 млн. евро до 133 млн. евро.

Варшава лидирует как площадка для украинских IPO. В 2010-11 гг. Варшавская фондовая биржа (WSE) стала основной площадкой для привлечения инвестиций украинских компаний: 5 из 6 IPO украинских компаний были осуществлены на WSE. На Варшавской фондовой бирже котируются акции таких украинских компаний, как “Астарта-Киев”, “Кернел-груп”, “Милкиленд”, “Садовая груп” и др. Эта биржа наиболее подходит для компаний с капитализацией \$100-150 млн. Кроме того, WSE занимает очень активную позицию по своему продвижению, открыв представительство в Украине. Варшавская биржа ближе и территориально, и ментально, польские инвесторы понимают специфику украинского бизнеса, систему ценообразования. Кроме того, требования к проспекту эмиссии на WSE очень близки к требованиям украинского законодательства.

В то же время, недавно в польском законодательстве произошли изменения, которые уменьшают спрос со стороны польских инвесторов, поскольку польским пенсионным фондам теперь запрещается покупать акции зарубежных эмитентов. Пенсионные фонды в прошлые годы показали себя активными инвесторами. Кроме того, в Польше уже в 2011 году были снижены нормы отчислений в пенсионные фонды, что негативно отразилось на их ликвидности. В силу этих причин, в 2012 году количество размещений на Варшавской фондовой бирже может пойти на спад, и украинским компаниям придется присматриваться к другим площадкам, в т.ч. Deutsche Boerse и Лондону.

Наиболее активними украинскими эмитентами на Варшавской фондовой бирже в 2011 году стали аграрные компании, которые привлекли \$150 млн., в том числе производитель яиц и яичных продуктов Ovostar Union (\$33 млн.), агропромышленная компания KSG Agro (\$ 39,6 млн.), агрохолдинг “Индустриальная молочная компания" (\$ 29,699 млн.). 
На главной площадке Варшавской биржи котируются ценные бумаги 435 компаний, в том числе 40 заграничных. Из 11 украинских компаний, которые продали акции в Варшаве в 2006-2011 годах, 8 представляют агросектор, 10 компаний котируются на главной площадке и входят в специально созданный индекс WIG-Ukraine.

Компаниям-эмитентам Украины рекомендуется выход на Варшавскую фондовую биржу в силу следующих факторов:

- относительно меньшая сумма затрат на размещение (первоначальный взнос 0,03\% (не менее 8 тыс. злотых и не более 96 тыс. злотых), ежегодный взнос 0,02\% (не менее 9 тыс. злотых и не более 70 тыс. злотых) );

- меньше минимальные требования для прохождения листинга;

- существует успешная история выхода на IPO украинских компаний, особенно агарного сектора;

- $\quad$ территориальная близость рынков Украины и Польши;

- $\quad$ стабильность, индекс WSE стабильно рос в период с января 2010 г. по июль 2011 г.;

- растущая перспективность биржи, особенно на фоне возобновления роста фондовых индексов;

- $\quad$ в 2011 г. WSE стала лидером в Европе по количеству размещений (41\% от общего количества IPO в Европе).

- $\quad$ первая по своим масштабам биржа в Центральной и Восточной Епропе.

\section{4. ПЕРСПЕКТИВЫ}

В мировом масштабе большое количество прибыльных компаний, нуждающихся в инвестициях, готовы к выходу на фондовую биржу.

Мировые и европейские тенденции рынка IPO свидетельствуют о, в целом, восходящем тренде, но наблюдаются периоды застоя и снижения. В ближайшие 2-3 года компании должны очень внимательно строить свои планы выхода. Требуется постоянный мониторинг мировых финансовых рынков, оценка инвестиционного спроса и предложения на рынке в разрезе отраслей и секторов.

Ожидается, что на вторичном рынке компании будут наращивать свою капитализацию до рекордных уровней, особенно для поддержки будущего приобретения.

Прогнозируется диверсификация IPO в разных секторах экономики, регионах и странах.

Для небольших компаний Варшава останется основной фондовой площадкой, а большие будут размещаться в Лондоне и Франкфурте.

Начало 2012 года дало поводы к оптимистическим ожиданиям перспектив развития мирового рынка IPO, благодаря проведению в Лондоне IPO компании "Руспетро" и всплеску IPO активности в США, включая размещение акций в рамках IPO компании Facebook. Эти сделки отражают некоторое улучшение тяжелой ситуации на рынке. Наметившаяся тенденция укрепилась также благодаря значительному росту биржевых индексов во всем мире в начале 2012 года.

В 2012 году оптимистичным фактором на рынке IPO является то, что около 200 компаний только в США планируют свои IPO в ближайшем будущем, а в целом более 700 компаний мира хотят привлечь около $\$ 112$ млрд в этом году. При этом 
может сохраниться тенденция выхода на IPO с небольшим (10\% или менее) пакетом акций, как это делали в прошлом году такие крупные компании, как Zillow, Groupon, Pandora и LinkedIn.

По мнению аналитиков, если на глобальном рынке IPO в 2012 году сохранятся неблагоприятные условия, то ожидается, что рынок IPO может ощутить давление со стороны конкурентных механизмов “частного размещения” (private placements).

Планируемые IPO украинских эмитентов: сельское хозяйство и АПК - 450 млн. USD, нефть и газ - 255 млн. USD, недвижимость и девелопмент - 100 млн. USD, другие отрасли - 26 млн. USD (всего 831 млн. USD).

Глава WSE Людвик Соболевский прогнозировал в 2012 году дебюты от 5 до 10 компаний из Украины. Представитель инвестиционной компании Quercus TFI Марек Бучак считает, что количество IPO украинских компаний на Варшавской фондовой бирже из-за плохой конъюнктуры и запланированных в Украине на октябрь 2012 года парламентских выборов, в лучшем случае, составит 1-2 после 6 дебютов в прошлом году. Инвесторы, покупающие акции на польском фондовом рынке, будут осторожнее относиться к покупке бумаг компаний из Украины из-за разочаровывающих результатов большинства украинских фирм, дебютировавших на WSE за последние два года. Вместе с тем, если появятся хорошие фирмы, появится и интерес к ним со стороны польских инвесторов. В целом, в случае улучшения конъюнктуры можно прогнозировать активизацию IPO украинских компаний на WSE в 2013-14гг.

Для перспектив выхода украинских аграрных компаний на WSE большое значение будет иметь: когда и в каком формате начнет действовать рынок земли в Украине; четкость прописанных правил на рынке земли; прозрачности аграрной политики государства, в т.ч. невмешательство в экспортную политику; оживление роста внешних рынков. В случае быстрого возобновления рынков в 2012 году можна ожидать до 15 новых размещений. Общий объем IPO может превысить \$4млрд., если будут реализованы планы выхода нескольких крупных компаний, каждая из которых может привлечь около \$ 1 млрд. Также в текущем году эксперты прогнозируют несколько размещений на внутреннем рынке. Внутренние IP0 станут хорошей возможностью для небольших и средних компаний, которым нужны привлеченные средства на сумму \$ 15-30 млн.

\section{5. ВЫВОДЫ}

На мировых рынках IPO наметилась слабо выраженная тенденция к оживлению и активизации. Вместе с тем, высоким остается уровень неопределенности, волатильности и рисков. Основная рекомендация для компаний, которые планируют привлечение средств через выход на международные рынки IPO, достичь стадии готовности и поддерживать ее до момента открытия “окна возможностей” для проведения IPO. Компаниям необходимо заблаговременно завершить основную работу по подготовке к выходу на международные фондовые рынки, чтобы не упустить момент благоприятной рыночной конъюнктуры. Компании должны проанализировать все альтернативные способы привлечения финансирования. Компании кандидаты на IPO должны иметь очень взвешенные и реалистичные ожидания относительно оценки их стоимости с учетом рисков. Также, с целью успешного выхода на IPO они должны формировать 
положительный деловой и социальный имидж, проводить активную рекламную кампанию, наладить систему коммуникации с інвесторами. Необходимо обеспечить рентабельность компании на уровне выше среднерыночного, повышать инвестиционную привлекательность, заинтересовать потенциальных инвесторов стабильной прибыльностью, амбициозными и убедительными инвестиционными планами в растущем и перспективном рыночном сегменте.

\section{ЛИТЕРАТУРА}

[1] Ernst\&Youngst. Global IPO Trends 2012: Ernst\&Youngst, 2012. - 28 p.

[2] PriceWaterHouse\&Coopers. IPO watch Europe 2011: PriceWaterHouse\&Coopers, 2012.- 30 p.

[3] Официальный сайт Варшавской фондовой биржи: http://www.gpw.com.pl.

[4] Елена Лебедева, Тенденции на рынках IPО в мире и СНГ, http://www.ipocongress.ru

\section{PERSPECTIVES OF THE UKRAINIAN COMPANIES ENTRANCE INTO THE GLOBAL IPO MARKETS}

In the article the modern tendencies of the global IPO market are considered. The practical recommendations regarding successful entrance of the Ukrainian companies into the global IPO markets are justified.

DOI: 10.7862/rz.2012.zim.26 